\title{
HIV and AIDS risk perception among sex workers in semi-urban Blantyre, Malawi
}

DONATIEN TWIZELIMANA ${ }^{1,2}$ and ADAMSON S. MUULA ${ }^{1 *}$

${ }^{1}$ Department of Public Health, School of Public Health and Family Medicine, College of Medicine, University of Malawi, Private Bag 360, Chichiri, Blantyre 3, Malawi

${ }^{2}$ Mlambe Mission Hospital, Lunzu, Blantyre, Malawi

\section{Abstract}

Background: Several health behaviour theories propose that risk perception affects the likelihood of behaviour intentions and practice. The perception of risk to HIV and AIDS among female sex workers in Malawi has not been well described. Yet knowledge of how this most at risk population perceives contagion could help in informing the design, implementation and monitoring of interventions.

Methods: A cross sectional, qualitative study was conducted among female sex workers in Blantyre, Malawi between 2013 and 2014. Snowballing technique was used to recruit study participants. In depth interviews were done by six trained female research assistants among 45 female sex workers. Data were analysed using thematic content analysis.

Results: There were mixed perceptions of risk to HIV infection among the sampled sex workers. While some of the study participants perceived themselves as at higher risk of acquiring infection, some considered themselves to be at no higher risk than the general population. Some study participants suggested that married women in stable relationship were at higher risk of infection than the female sex workers. Prayer and belief in God were reported to be protective from HIV acquisition while predestination or mere talking about HIV was perceived to result in vulnerability to infection. In terms of overall knowledge about HIV, this was assessed as high. Several barriers to consistent condom use were reported: non-availability at all times, high cost and unacceptable instructions of the female condom, offers of higher pay for unprotected sex by male clients and harassment and forced unprotected sex by police.

Conclusions: We have reported expression of dissonance, fatalism and predestination among female sex workers in semi-urban Malawi is responses to the threat of HIV. There is need to develop context-specific safer sex programs among female sex worker in Malawi.

Keywords: Sex workers, HIV/AIDS, risk perception, condom use, Malawi

\section{Introduction}

Several behavioural change theories or frameworks suggest that risk perception and self-efficacy are crucial if the individual should avoid exposure to harmful behaviours or lifestyles (Becker, 1974; Maiman \& Becker, 1974; McAlister et al., 2008). Female sex workers are at increased risk of HIV and other sexually transmitted infections (STIs) acquisition and transmission largely because their lifestyle or work involve multiple and concurrent and transient sexual partnerships. Multiple partnerships, defined as sexual partnerships overlapping in time are key drivers for HIV transmission and acquisition (Deuchert \& Brody, 2007; Lurie \& Rosenthal, 2010; Mah \& Halperin, 2010; Sawers et al., 2010; Sawers \& Stillwagon, 2010). The higher than average risk is explained by inconsistent condom use arising from non-availability, cost, client preference, poverty, compromised negotiation skills and power imbalances within parties (Lawan et al., 2012; Popoola, 2013; Zhang et al., 2013).

Bowie and Maleta (2010) have reported that much of the HIV transmission in Malawi occurs within stable relationships. However, high risk of HIV transmission among clients of female sex workers has been reported in the country and elsewhere (Bowie \& Maleta, 2010; Chow et al., 2015; Githuka et al., 2014; Leclerc \& Garenne, 2008). The current study was conducted in semi-urban Blantyre (Lunzu), Malawi to assess HIV and AIDS risk perception and self-efficacy to prevent contagion among female sex workers. Knowledge about risk perception could inform

\footnotetext{
*Correspondence E-mail: amuula@medcol.mw
} 
strategies aimed at promoting sexual (and other) health of female sex workers, clients and the wider community indirectly connected through sexual networks.

\section{Materials and Methods}

\section{Study design and data collection}

This was a cross sectional, qualitative study conducted in semi-urban area of Lunzu in Blantyre Malawi. The first 10 female sex workers were selected through convenient sampling from a known group (of female sex workers) which is assisting Mlambe Hospital's health care providers in health promotion activities. The sample study had a mixture of brothel-based and street-based and casual sex workers. We used an age restriction of between 15-50 years. These study participants were then asked to invite colleagues through a snowballing technique Recruitment continued until there was saturation and redundancy in the data being collected. In total 45 female sex workers were recruited.

Six female research assistants were involved in data collection: two were taking notes the other two were facilitating the discussions and the remaining two were sound recording the conversation. We used female research assistants because the respondents were not comfortable with male research assistants. We also believed that female sex workers would be more candid when interviewed by other women. On average one hour was used for every interview.

Qualitative data were collected using in-depth interview with interview's guide in local language (Chichewa). Transcripts were later translated into English before analysis. The interviews explored the following topics: general socio-economic/demographic background of the informant such as age and education; questions on perceived susceptibility (e.g. some people say that sex workers are at high risk of being infected with HIV. What is your opinion?; Perceived severity (e.g., What do you think about this statements?: HIV is a killer or if I had AIDS my life will end soon?); perceived benefits (e.g. what do you think about the benefits of using a condom?); self-efficacy (in case your client refuses to use a condom how can you convince him to use the condom?). Other topics discussed were: awareness about HIV, the nature of the sex work, HIV stigma and discrimination and HIV risk reduction strategies.

\section{Data analysis}

Data were analysed using thematic content analysis relating to the objectives of the study (Mayring, 2000). An interpretative thematic approach to analysis was used (Seale, 2004). This is used as reflexive and iterative process with initial open coding (reading through the text first) followed thereafter by selective and more detailed coding. Relationships and comparisons were then made between themes, across participants, and with the wider literature of female sex workers. Findings were reviewed in the research team and a much more comprehensive understanding of the data emerged.

Each transcript was read and the text was divided into meaningful units. We looked for consistent patterns within the data for similarities and differences in the responses that respondents made in their interviews. Once all the meaningful units in the transcripts were separated out, we worked through the text looking for meaningful units that grouped together; then we wrote down the words that summarized the themes that were discussed in the interview transcripts. We then agreed on the coding, analysis, interpretation and addressed discrepancies which required clarity. Representative or exemplar quotes that best describe the categories were agreed upon by the authors and selected for presentation.

\section{Ethical considerations}

The study protocol was reviewed and approved by the College of Medicine Research and Ethics Committee (COMREC) of the University of Malawi, College of Medicine. We assured respondents of confidentiality of the information and privacy of the research participants. We assured the 
study participants that we were not going to inform law enforcements on the identification of the sex workers. Study participants were recruited through snowballing where initial sex workers identified talked to colleagues and recruited them into the study. Study participants were informed of the study and requested to volunteer. For their time, the study participants were given laundry or toilet soap, drinks and snacks.

\section{Results}

\section{Socio-demographic characteristics of the sample}

Forty-five female sex workers participated in the study; age ranged from 17-40 years. None reported being married and 23 were Christians and 22 were Muslims. Most (28) of them being in their twenties. Twenty-nine had only primary school education and 10 had Junior Secondary School Certificate, seven refused to answer on their level of education. Study participant reported selling sex not only in the study area but also outside the study to locations as far as distances of over 20 kilometres.

\section{Perceived lower risk of HIV acquisition and transmission}

Some respondent reported that sex was not the only mode of HIV transmission. The emphasis placed on health education by HIV prevention programs toward sexual transmission of HIV was therefore perceived as misplaced. "I heard that people can be infected by HIV through blood transmission, this means that they are other modes of transmission....." (24 years old study participant). "My sister was sick at our Hospital she got many injections of quinine, her buttocks were swollen and there was pus inside. Later the doctor did HIV test she was positive and the husband is negative, she got HIV from the same injections.... (16 years old study participant).

There was also reported misconception on the modes of HIV transmission. "HIV is found in the blood that is why even mosquitoes can transmit it because they suck blood and inject it in other people..." (17 years old study participant).

Some study participant reported that the risk of being infected with HIV among sex workers was lower compared to the women who were not sex workers. The study participant reported that they were taught how to use condoms to protect them against HIV. They suggested that many married women did not know a condom and how to use it.

\section{Stigma and discrimination}

Some participants suggested that the prevailing understanding that sex workers were fuelling the spread of HIV was misguided. The media was specifically identified as responsible for spreading negative attitudes toward sex workers in terms of crime and HIV transmission. Police harassment and stigmatization and discrimination by health workers against sex workers were also reported. "Once we are arrested by the police officers, they force us to have sex with them free of charge so that we can be released. Nobody talks about those police officers, people always blame us... "(27 years old study participant). Another participant, added: "One priest in............died of AIDS... It is the disease of everybody..." (30 years old)

\section{Divine protection and sources of support}

Many of the study participants reported attending religious meetings and services, and engaging in prayer so that God could protect them against HIV infection. Study participants believed that God was the "only" reliable source of protection. "My church members know that I am a sex worker, I always go to church on Sunday to ask God's forgiveness and protection. Without God you can easily catch HIV, but with him you can't..." (32 years old study participant). "God is always on our side we pray together so that God should not allow bad things to happen to us....." (26 years study participant). Other participants had these to add: "God knows good and bad things including HIV as long as you praise him He will not allow bad things such as HIV to happen to you....." (31 years old). "Some couples living together we heard that one person can be HIV positive while the 
other one is HIV negative, those are miracles of God" (30 years old). "In Jesus name I will never get HIV...." (30 years old). "God always loves his people without segregation; some people were cured from HIV because of prayers here in Malawi even in Nigeria. Watch Emmanuel TV you will see them." (30 years old).

\section{Predestination of HIV acquisition and fatalism}

Several study participants observed that persons who die from AIDS have already been predestined. Consequently it was futile taking preventive measures if an individual's outcome had long since been decided. "Whether you use condoms or take the medicines if God doesn't want you to be infected and become sick, it will not happen to you...." (25 years old). Another participant had these to say: "For each and everyone here, God mapped up the cause of her death therefore it is a waste of time to avoid it. If I will die because of malaria, accident, cholera or AIDS there's nothing I can change on my own...." (20 years old). Some study participants reported talking about HIV was not advisable as doing so would only make it more likely that one is infected. "An evil is an evil don't talk about it otherwise it will one day come to your home...." (23 years old).

\section{Access to, and attitudes toward, condom use}

Study participants reported regular condom use during sexual intercourse. They reported that this is important so as to prevent unwanted pregnancies, sexually transmitted infections and HIV. All participants reported knowledge of male condoms which they often carried on their person; female condoms were neither preferred nor always available. Female condoms were reported as expensive and not user friendly. "You can't know how many condoms your client will use; to be on the safe side it is better to carry yours..." (20 years old). "Female condoms have many rules therefore they are not convenient to use and also they are very expensive. We can't afford to buy them, and they are not easily found..." (29 years old). "I always tell my clients to use condoms because I don't want to be pregnant..." (25 years old). "If you don't use the condom, you can easily become pregnant and you feel very bad to have the baby with an unknown father..." (23 years old).

\section{Barriers to condom use}

Study participants reported that they may not use condoms because of: clients' requests, extra payments if the woman accepts sex without a condom and inaccessibility of condoms especially during the night when the nearest shops and bars were closed. Sex workers reported that the more money their clients pay, the more they (client) will dictate the terms of the sexual act, even if it meant not using condoms. Some men may not pay after sex in case they refuse to have sex without condoms. "Most of our clients say that they don't enjoy sex when they are using condoms and we agree to have sex without condoms because failure to do that they go somewhere else..." (17 years old). "If a man doesn't want to use a condom and he tells you that he will give you K $20,000.00$ if you accept to have sex without a condom and that particular day maybe you don't have money to buy food, you accept the offer so that you are able to buy food for you and your children..." (30 years old).

\section{Overall perceptions towards HIV and AIDS}

Study participants described how someone suffering from AIDS looks like and they said that AIDS is a disease they were familiar with. Contrary to the belief that there was high stigma and discrimination against people living with HIV and AIDS, most study participants reported that AIDS was like any other disease. They said that it was not only AIDS which had no effective cure. Compared to other diseases, the study participants reported that the effects of HIV infection were longer term than short or immediate term consequences of other infections or diseases. Study participants reported that malaria, cholera, tuberculosis, swelling of the lower limbs and other sexually transmitted diseases had less grave consequences than AIDS. "Suppose that you are in our situation what will you prefer (asking one of the research assistant) and during the same 
period no extra income; but maybe all of us here (sex workers) we have HIV and AIDS but these don't affect us when we are looking for money. Men don't ask us if we have HIV or not. How can someone sleep with you if you have cholera or you are bed ridden? (24 years old). "All deaths are the same; either you die because of AIDS, road traffic accidents malaria still it is death." (16 years old).

\section{Discussion}

In a qualitative cross sectional study of 45 female sex workers in semi-urban Blantyre, Malawi, we found that study participants had mixed perception of the severity of HIV, their own vulnerability and efficacy towards condom use. While study participants were able to discuss the modes of transmission of HIV, there were also misconceptions and/or inappropriate interpretation of the knowledge/information. For instance concerning unsafe blood transfusions, injections and marital sex contributing to HIV transmission, study participants interpreted these modes are possibly higher or at least equal in important as sex work. That much of HIV transmission in Malawi occurs within stable marital union has been reported by Bowie \& Maleta (2010) may not be interpreted that sex work is safer. The absolute number of HIV transmission occurs within marriage largely because there is more unprotected sexual intercourse within marriage than among any other relationships.

Ankomah et al. (2011) concluded in a study from Nigeria "that sex workers underestimated their risk of infection and rationalized, defended, or justified their behaviours, a typical psychological response to worry, threat, and anxiety arising from the apparent discrepancies between beliefs and behaviours." Further, these authors reported that "to reduce dissonance, many sex workers had a strong belief in fatalism, predestination, and faith-based invulnerability to HIV infection. Many believed that one will not die of acquired immune deficiency syndrome if it is not ordained by God."

In a study of male sex worker in Lebanon, Aunon et al. (2015) found similar perceptions among these men where resignation and fatalism were reported to influence non-use of condoms. Muñoz et al. (2010) in their study of sex workers and risk assessment for HIV transmission reported five themes which emerged from their study. There were: (i) flawed knowledge and fatalistic attitudes; (ii) the psychosocial and economic context of sex work; (iii) religious beliefs, stigma and risk taking; (iv) barriers to HIV testing; and (v) legal and policy constraints to sex work. We found similar perceptions and rationalizations among sex workers in Malawi, who reported that all deaths were the same, God would protect them and that if one was predestined to be infected, and then it was futile to take preventive measures. Despite such observations, study participants in our study reported intentions to use condoms are identified barriers to use they considered beyond their control. The question that remains is: if sex workers believed in predestination, why were they taking efforts to use condoms?

Kalanda (2010) has reported on a program in Dowa district in central Malawi where female sex workers were trained and supported to contribute to HIV prevention and safer sex among their peers. Understanding the determinants of unsafe sexual practices among female sex workers as we have done in this study has potential to better inform preventive efforts. While Richards (2004) has reported on a study where HIV and AIDS were reported to be a curse from God (i.e. the source of infection), our study participants reported praying to God for protection from HIV acquisition. God was never identified by the study participants in our study as "making" sex workers infected; rather he was identified as a protector.

This study had several strengths and limitations. The first strength is that we collected data until the points of saturation and redundancy. This would suggest that in this setting the key perceptions among the study participants were collected. Secondly recruitment was through snow balling from one sex worker to another. This approach probably meant that we were more likely to recruit sex workers who felt secure and not threatened, knowing that prostitution is 
illegal in Malawi. In terms of limitations, data were self-reported without further triangulation as this was not possible. Secondly, we interviewed study participants who were within reach through the snow balling recruitment technique. Our study participants were therefore sex workers who were known or were friends to, or belong to the network of our initial recruit.

We also did not interview clients of sex workers or professions (e.g. health workers and law enforcement) who were mentioned by the study participants as intimidating or discriminating against them. The full diversity of opinions may not have been captured. Finally, we only sampled female sex workers. The perceptions of male or transgender sex workers were not included.

We have reported expression of dissonance, fatalism and predestination among sex workers in semi-urban Malawi is responses to the threat of HIV. Based on the above findings it is very unlikely that female sex workers can easily change their behaviour (selling sex in the exchange of money or goods). There is need to develop context-specific safer sex programs among sex worker in Malawi. Interventions on HIV and AIDS should focus more on the promotion of condom use as well as on self-efficacy. Sex work affords female sex workers more financial benefits. It will be a challenge to health promotion interventions targeting FSWs if other means of survival such as small scale business are not initiated in the same community. Health promotion programmes should also set up interventions to combat a fatalistic believes, predestination and dissonance

\section{Authors' contributions}

DT designed the study, collected and supervised data collection, analysed the data and contributed to drafting of the manuscript. ASM supervised all the stages of the study and drafted initial version of the manuscript. Both authors agreed to final draft of the manuscript.

\section{Acknowledgements}

We thank all the study research assistants and the study participants in the study.

\section{References}

Ankomah, A., Omoregie, G., Akinyemi, Z., Anyanti, J., Ladipo, O. \& Adebayo, S. (2011) HIV-related risk perception among female sex workers in Nigeria. HIV AIDS (Auckl) 3:93-100.

Aunon, F.M., Wagner, G.J., Maher, R., Khouri, D., Kaplan, R.L. \& Mokhbat, J. (2015) An exploratory study of HIV risk behaviors and testing among male sex workers in Beirut, Lebanon. Social Work in Public Health 30, 373-84.

Becker, M. (1974) The Health Belief Model and Personal Health Behavior. Health Education Monograph 2, 236-473.

Chow, E.P., Muessig, K.E., Yuan, L., Wang, Y., Zhang, X., Zhao, R., Sun, P., Sun, X., Tucker, J.D., Jing, J. \& Zhang, L. (2015) Risk behaviours among female sex workers in China: a systematic review and data synthesis. PLoS One 10(3):e0120595.

Deuchert, E. \& Brody, S. (2007) Plausible and implausible parameters for mathematic modeling of nominal heterosexual HIV transmission. Annals of Epidemiology 17, 237-244.

Githuka, G., Hladik, W., Mwalili, S., Cherutich, P., Muthui, M., Gitonga, J., Maina, W.K., Kim, A.A., KAIS Study Group (2014) Populations at increased risk for HIV infection in Kenya: results from a national population-based household survey, 2012. Journal of Acquired Immune Deficiency Syndrome 66 (Suppl 1), S46-56.

Kalanda, B. (2010) Empowering young sex workers for safer sex in Dowa and Lilongwe Districts of Malawi. Malawi Medical Journal 22, 10-11. 
Lawan, U.M., Abubakar, S. \& Ahmed, A. (2012) Risk perceptions, prevention and treatment seeking for sexually transmitted infections and HIV/AIDS among female sex workers in Kano, Nigeria. African Journal of Reproductive Health 16, 61-67.

Leclerc, P.M. \& Garenne, M. (2008) Commercial sex and HIV transmission in mature epidemics: a study of five African countries. International Journal of STD and AIDS 19, 660-664.

Lurie, M.N. \& Rosenthal, S. (2010) Concurrent partnerships as a driver of the HIV epidemic in subSaharan Africa? The evidence is limited. AIDS and Behaviour 14, 17-24.

Maiman, L.A. \& Becker, M. (1974) The Health Belief Model: origin and correlates in psychological theory. Health Education Monograph 3, 336-353.

Maleta, K. \& Bowie, C. (2010) Selecting HIV infection prevention interventions in the mature HIV epidemic in Malawi using the mode of transmission model. BMC Health Services Research 10:243.

Mayring, P. (2000) Qualitative Content Analysis. Forum Qualitative Sozialforschung / Forum: Qualitative Social Research 1(2), Art. 20, http://nbn-resolving.de/urn:nbn:de:0114fqs0002204.

McAlister, A.L., Perry, C.L., Parcel, G.S. (2008) How Individuals, Environments, and Health Behaviors Interact: Social Cognitive Theory. In: Health Behavior and Health Education: Theory, Research, and Practice 4th Edition. San Francisco, CA: John Wiley \& Sons, Inc: 169188.

Muñoz, J., Adedimeji, A. \& Alawode, O. (2010) 'They bring AIDS to us and say we give it to them': Socio-structural context of female sex workers' vulnerability to HIV infection in Ibadan, Nigeria. SAHARA J: Journal of Social Aspects of HIV/AIDS 7:52-61

Richards, S. (2004) God's curse and hysteria: women's narratives of AIDS in Manokwari, West Papua. Papua New Guinea Medical Journal 47, 77-87.

Sawers, L., Isaac, A. \& Stillwaggon, E. (2011) HIV and concurrency: modeling the role of coital dilution. Journal of the International AIDS Society 14,1-9.

Sawers, L. \& Stillwaggon, E. (2010) Concurrent sexual partnerships do not explain the HIV epidemics in Africa: a systematic review of the evidence. Journal of the International AIDS Society $13,1-23$.

Seale, C. (2004) Social Research Methods: A Reader. London: Routledge.

Popoola, B.I. (2013) Occupational hazards and coping strategies of sex workers in south-western Nigeria. Health Care for Women International 34, 139-149.

Zhang, C., Li, X., Hong, Y., Zhou, Y., Liu, W. \& Stanton, B. (2013) Unprotected sex with their clients among low-paying female sex workers in southwest China. AIDS Care 25, 503-506. 